\title{
Microwave-assisted Rapid and Green Synthesis of $k$-carrageenan Gum Capped AgNPs for Enhanced Bactericidal Efficacy
}

\author{
Elvis Fosso-Kankeu, Rainere D.P. Cilliers, Sadanand Pandey*, Misook Kang and Frans Waanders
}

\begin{abstract}
The current paper presents the synthesis of simple, rapid, low cost, eco-friendly kappa carrageenan gum (CG) capped silver nanoparticles (AgNPs) (CG-capped AgNPs) using biopolymer, CG. The physico-chemical characterization was done using Ultraviolet-visible spectroscopy, Fourier-transform infrared spectroscopy (FTIR), scanning electron microscopy (SEM), X-ray Powder Diffraction (XRD) and zeta potential $(\zeta)$. The $r$ results of the spectroscopy characterization (SEM and XRD) revealed that the nanoparticles are spherical in shape and was gathered by face cantered cubic (FCC) structure throughout the polymer matrix and stable without any protecting or capping reagents over many days. The antibacterial efficacy of these CG capped AgNPs as well as selected antibiotics was evaluated against Escherichia coli by agar well diffusion test, promising antibacterial potential was therefore observed.
\end{abstract}

Keywords-Biopolymer, Microwave irradiation, metal nanoparticle, antimicrobial activity, green synthesis,

\section{INTRODUCTION}

Water is a diminishing resource that remains vital to the social, ecological and physical wellbeing of modern society. As a country labelled to be semi-desert, South-Africa, has an impending water scarcity problem [1-15]. Government statistics indicate that $11.4 \%$ of citizens don't have access to piped water arising from sources such as dams, rivers or underground water [16]. Pollution of public water sources, through sewage spillages, amplifies this problem for those dependent on rivers like the Vaal River as their main water source [17]. Many people make use of the Vaal River, untreated by conventional water treatment methods such as chlorination and by doing so, expose themselves to health risks [17]. E.coli

R.D.P. Cilliers is with the Water Pollution Monitoring and Remediation Initiatives Research Group, School of Chemical and Minerals Engineering, North-West University, Potchefstroom-South Africa.

Elvis Fosso-Kankeu is with the Water Pollution Monitoring and Remediation Initiatives Research Group, School of Chemical and Minerals Engineering, North-West University, Potchefstroom-South Africa.

*Sadanand Pandey is with the Department of Chemistry, College of Natural Science, Yeungnam University, 280 Daehak-Ro, Gyeongsan, Gyeongbuk, 38541, Republic of Korea.

Misook Kang is with the Department of Chemistry, College of Natural Science, Yeungnam University, 280 Daehak-Ro, Gyeongsan, Gyeongbuk, 38541, Republic of Korea

Frans Waanders is with the Water Pollution Monitoring and Remediation Initiatives Research Group, School of Chemical and Minerals Engineering, North-West University, Potchefstroom-South Africa is an infectious pathogen that leads to severe illness and if untreated, an infection could be fatal [18]. E.coli serves as an indicator that faecal matter is abundantly present in a river system [19]. Alarmingly, E.coli concentrations have reached upwards of 241000 counts per $100 \mathrm{~mL}$, while a concentration deemed to be safe for use is typically 130 counts per $100 \mathrm{~mL}$ [20]. The Emflueni municipal waste water treatment plant is the main source of sewage spillages into the Vaal River [20]. Due to mismanagement, and traditional waste water treatment technologies becoming ineffective, new solutions for treating waste water are required [21]. Nanotechnology is a relatively new novel technology that expands on the water treatment methods ensuring that a stable supply of drinking water to communities can be maintained [22]. This research aims to determine the antimicrobial activity of silver nanoparticle (AgNPs) produced using the facile green synthesis method of microwave radiation in the presence of $\kappa$-carrageenan gum (CG) biopolymer as a reducing and stabilising agent. The chemical structure of CG is shown in (Fig.1a).

The properties of nanomaterials differ significantly from their macro-particle counter parts [23-39]. The main factors influencing the properties of these particles include the size, shape and morphology of the nanomaterials. The high surface to volume ratios of nanoparticles are responsible for their size dependent properties like high reactivity, fast dissolution and strong sorption. Nanoparticles impregnate the surface of stabilizing materials, keeping the individual particles from agglomerating. The choice of stabilizing agent has an immense effect on the properties of the nanoparticles produced. This is especially true over time. The long-term problem associated with nanotechnology is stability. The two main ways stability is characterized are electrostatic and steric stability [40]. The high surface areas, result in poor colloidal stability, which leads to the eventual agglomeration in solution [41]. This, over time, increases the particle size and therefore changes the properties of the original nanoparticle. Logically this is not ideal if the nanoparticles were produced with a specific task in mind. In order to circumvent this problem, biopolymers have often been used as an outer shell coating onto which the nanoparticle cores are placed. This provides steric (in some cases electrostatic or even electrosteric) barriers to agglomeration-imparting stability to the nanoparticles [41]. If chosen correctly the stabilizer could also serve as the reductant, hereby imparting unique properties to the produced particles. Nano materials, such as AgNPs, are well known for their antimicrobial effects and have the potential to be applied in water purification. Harmful 
biological contaminants can be removed from wastewater treatment plant effluent by integrating nanotechnology into the local waste water treatment methods [22].

The different synthesis methods by which AgNPs are produced are quite extensive. The methods can traditionally be characterized under two different styles, Physical methods and chemical methods [40]. A third classification is biological method using biomaterials. In recent years, this method has been gaining special attention because of cost effectiveness, non-toxic and biocompatible nature of these biomaterials [42, 43].

The physical methods include evaporation, condensation and laser ablation. These methods require large workspace, are energy intensive, and suffer from excessive preheating time requirements for thermal stability.[40], also suggests three different types of chemical methods: Classic chemical (reducing agents), radiation-chemical (the reducing process is initiated by solvent electrons generated by ionizing radiation) and the use of naturally occurring reducing agents (such as polysaccharides).

The most common method for the production of AgNPs falls under the classification of classic chemical [44]. In this method, a silver salt is dissolved with a reducing compound (such as $\mathrm{NaBH}_{4}$, citrate hydrazine, glucose or ascorbate) in water. Strong reductants produce small monodispersed particles. These are fast reactions generating particles of a larger size, which is a difficult form with regard to control point of view [44]. Slower reduction reactions due to the use of weaker reductants are easier to control. The slower produced nanoparticles tent to be more polydisperse in terms of size. To control the size of the produced nanoparticles, a 2 stage mechanism is proposed: the use of a strong reductant to produce very small nuclei, where after a slower reacting weak reductant is used to enlarge the particle size [44].

The aforementioned methods have proved to be effective, but since the reducing agents used, are commonly considered toxic or hazardous, great emphasis has fallen on green synthesis methods in recent years. In recent years green synthesis methods included the use of Barleria longiflora L. leaves, organic solvent with aqueous green marine algae (chaetomorpha sp.), Malus domestica, aqueous extract from Forsythia suspense fruit and microwave assisted synthesis utilising an aqueous extract of Rosa santana (rose) petals [45]-[49]. In particular the microwave-assisted synthesis is of interest because the particles produced by [49] were tested on a mouse fibroblast cell line (L929) and it was concluded that these particles did not have any negative cytotoxic effect. Using naturally occurring reducing agents, coupled with technology like microwave radiation [50-52], allows for green, facile production of silver nanoparticles [53]. This method affords the producer of a shorter reaction time, lower energy consumption and better product yield [53]. The process doesn't warrant large equipment. Most operations can be completed in a common household microwave. The fact that no waste is produced and due to the ease of scalability provided by the great penetration of the microwaves, this method could be easily applied to WWT plants [54]. The present study is aimed at the rapid synthesis of AgNPs using economically abundant biopolymer kappa carrageenan gum. The Ag NPs were characterized by
UV-visible spectroscopic analysis followed by Fourier transform infrared (FTIR), X-ray diffraction (XRD) etc. Furthermore, antimicrobial activity was tested using the prepared CG capped AgNPs.

\section{EXPERIMENTAL: MATERIAL AND REAGENTS}

All chemicals used were of analytical grade and supplied by either Sigma-Aldrich, Minima Chemicals, Davies Diagnostics (Ltd) Pty. SA, or ACE.

\section{INSTRUMENTS}

Zeta potential analysis was done on a Particulate Systems NanoPlus zetta/nano particle analyser using a flow cell for 400 $\mu \mathrm{s}$ at a scattering angle of $15^{\circ}$ with an intensity of $78536 \mathrm{cps}$ and an average negative electric field of $-16.66 \mathrm{~V} / \mathrm{cm}$ in a water-based diluent at $25^{\circ} \mathrm{C}$. FTIR spectra were recorded on a Spectrum-100 Perkin Elmer, USA. The surface morphologies of the samples were examined by a scanning electron microscopy (SEM), (TESCAN, VEGA SEM) under a $20 \mathrm{kV}$ electron acceleration voltage. To avoid charging, these samples were coated with carbon. X-ray diffractometer was employed for acquiring XRD pattern with a Rigaku Ultima IV, X-ray diffractometer, Japan. $\mathrm{pH}$ measurements were done using a HANNA HI8424 pH meter under standard conditions. Autoclave sterilisations were done using a D\&E international Corp. model HL-341, the incubation oven used was a Labcon shaking incubator. All optical density measurements were made using a Thermo scientific Genesis 10S UV-Vis spectrophotometer at a wave length of $600 \mathrm{~nm}$. All weight measurements were made using a Mettler Toledo AE100 scale.

\section{SYNTHESIS OF METAL NANOPARTICLES}

The nine different combination of $\kappa$-carrageenan capped AgNPs were made. The CG concentrations used were $0.1,0.2$ and 0.3 $\mathrm{g} / 50 \mathrm{~mL}$ solution. For each of these, the silver nitrate concentrations used were 20,40 and $60 \mathrm{mg} / 50 \mathrm{~mL}$ solution.

The CG was added to $20 \mathrm{~mL}$ of distilled water and shook in an automatic shaker until it became homogeneous (1 hour). This was done for each concentration of CG. The silver nitrate salt was added to $10 \mathrm{~mL}$ of distilled water and shook until completely dissolved. This was done for each concentration of silver nitrate. The $\mathrm{pH}$ was adjusted to 8 by adding $100 \mu \mathrm{L}$ of sodium hydroxide to the silver nitrate solutions. The CG solutions and the silver nitrate solutions were then combined, and distilled water was added until a total solution volume of 50 $\mathrm{mL}$ was obtained. Therefore, the solutions that were made were $(0.1 \mathrm{~g}$ k-carrageenan-20 mg silver nitrate $) / 50 \mathrm{~mL},(0.1 \mathrm{~g}$ $\kappa$-carrageenan-40 $\mathrm{mg}$ silver nitrate $) / 50 \quad \mathrm{~mL}, \quad(0.1 \mathrm{~g}$ $\kappa$-carrageenan- $60 \mathrm{mg}$ silver nitrate) $/ 50 \mathrm{~mL}$. This set of varying silver nitrate solutions was repeated for both 0.2 and $0.3 \mathrm{~g}$ of CG. These solutions were mixed twice for 1.5 hours at $200 \mathrm{rpm}$. The solutions were exposed to microwave oven $(900 \mathrm{~W})$ for 80 seconds. The colour of the solutions was continuously monitored as a change to dark brown was synonymous to a successful reaction. The reaction occurred at a temperature of $42^{\circ} \mathrm{C} \pm 1^{\circ} \mathrm{C}$. This synthesis process was performed in triplicate in each case. 
AGAR PLATE PREPARATION

Firstly, $28 \mathrm{~g}$ of nutrient agar powder was added to $1 \mathrm{~L}$ of DI water and mixed with a magnetic stirrer for $10 \mathrm{~min}$ before being sterilised in an autoclave at $121^{\circ} \mathrm{C}$ and $1.5 \mathrm{~atm} / \mathrm{cm}^{2}$ for $45 \mathrm{~min}$. A sterilized glass pipet was used to create a uniform $4 \mathrm{~mm}$ deep agar layer in the sterile petri dishes. After the agar had set, the petri dished were put in a sealed plastic container and stored at $4^{\circ} \mathrm{C}$ until used (within 1 week).

\section{NUTRIENT BROTH PREPARATION}

A $25 \mathrm{~g}$ of Lauria-broth powder was added to $1 \mathrm{~L}$ of distilled water and mixed with a magnetic stirrer for $10 \mathrm{~min}$ before being sterilised in an autoclave at $121^{\circ} \mathrm{C}$ and $1.5 \mathrm{~atm} / \mathrm{cm}^{2}$ for $45 \mathrm{~min}$. The broth was left to cool at room temperature and stored in a sealed glass bottle at $4^{\circ} \mathrm{C}$ until used (within 1 week).

\section{SUB-CULTURING THE BACTERIA}

To avoid contamination of the commercial E. coli $(\mathrm{O} 157: \mathrm{H} 7)$ culture a $0.33 \mathrm{~mm}$ sterilised nichrome wire was used to inoculate a petri dish with the gram-negative bacteria. The inoculated plate was incubated at $36{ }^{\circ} \mathrm{C}$ for $24 \mathrm{hrs}$. Cells from the petri dish were transferred to $200 \mathrm{~mL}$ nutrient broth in a sterilized Erlenmeyer flask using an inoculation loop and incubated at $36^{\circ} \mathrm{C}$ in an incubation oven with a mixer plate at 50 rpm for 24 hours.

\section{DISC DIFFUSION METHOD}

$100 \mu \mathrm{L}$ of the inoculated nutrient broth was added to $150 \mathrm{~mL}$ of fresh nutrient broth and incubated. The optical density $\left(\mathrm{OD}_{600}\right)$ was continuously monitored until an $\mathrm{OD}_{600}$ value of 1 (McFarland half standard) was reached. $100 \mu \mathrm{L}$ of the inoculated solution was then pipetted into the petri dishes, using sterile pipet tips. After flame sterilising a glass lazy-L-spreader and allowing to cool, the inoculum was uniformly spread over the entire surface of the agar. The glass spreader rod was submerged in a $70 \%$ ethanol solution and flame sterilised in between each plate to avoid cross contamination. Following the Dr Kirby Bauer disk diffusion method [55,56], the petri dishes were sub-divided and labled on the bottom before inoculation. After inoculation 3 equally spaced blank discs from Davis Diagnostics (Pty) Ltd., SA, were placed onto the agar and gently pressed using a flame sterilised tweezer. Each blank disc was then impregnated with $15 \mu \mathrm{L}$ of the antibacterial medium (CG capped AgNPs of different dilutions). Each of the AgNPs solutions was diluted to obtain a 1:0,1:1, 1:2 and 1:3 dilution with distilled water. The discs had a diameter of $6 \mathrm{~mm}$, and any inhibition was measured as a diameter where any measurement larger than $6 \mathrm{~mm}$ indicated inhibition. The inoculated petri dishes were incubated at $36^{\circ} \mathrm{C}$ for 20 hours. As a positive controls 2 commercial antibiotic disks, $100 \mu \mathrm{g}$ Carbenicillin and $30 \mu \mathrm{g}$ Vancomycin, were used. Chemical structure of (b) carbenicillin and (c) vancomycin are shown in Fig.1 (a)

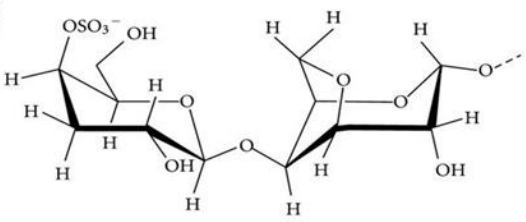

(b)

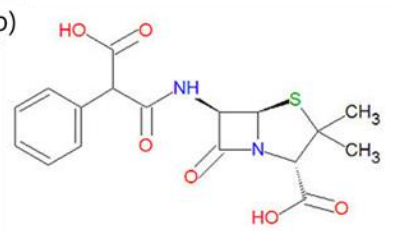

(c)

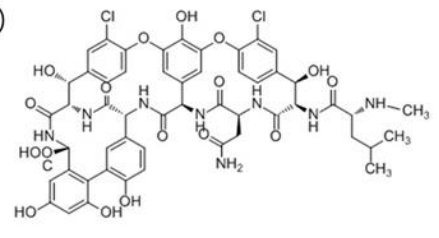

Fig. 1 Chemical structure of (a) $k$-Carrageenan gum; (b) Carbenicillin and (c) Vancomycin.

\section{RESULTS AND DISCUSSION}

The reduction of $\mathrm{Ag}^{+}$to $\mathrm{Ag}^{0}$ was primarily monitored by visual inspection of the reaction mixture. The color of the reaction mixture changed from colourless to dull yellow to brown colour within few seconds of microwave irradiation [57] (Fig.2a). This gave the preliminary confirmation of formation of CG capped AgNPs. In order to know the size, shape and distribution, SPR plays a very important role. AgNPs SPR properties with their morphology is a fast and easy way for in situ monitoring of the synthesis by UV-visible spectroscopy [58]. This is very useful, for instance, in the early stages of wet chemistry synthesis, when many different chemicals are present in solution and sample preparation for transmission electron microscopy (TEM) analysis poses serious concerns about particles modification. The change in color has been attributed to excitation of surface Plasmon resonance (SPR) of AgNPs [57]. The SPR of different combination of $\mathrm{CG}$ capped AgNPs was observed in the wavelength region between $420 \mathrm{~nm}-430 \mathrm{~nm}$ which confirms the synthesis of AgNPs. SPR also shows the spherical shape of formed AgNPs (Fig.2b). 

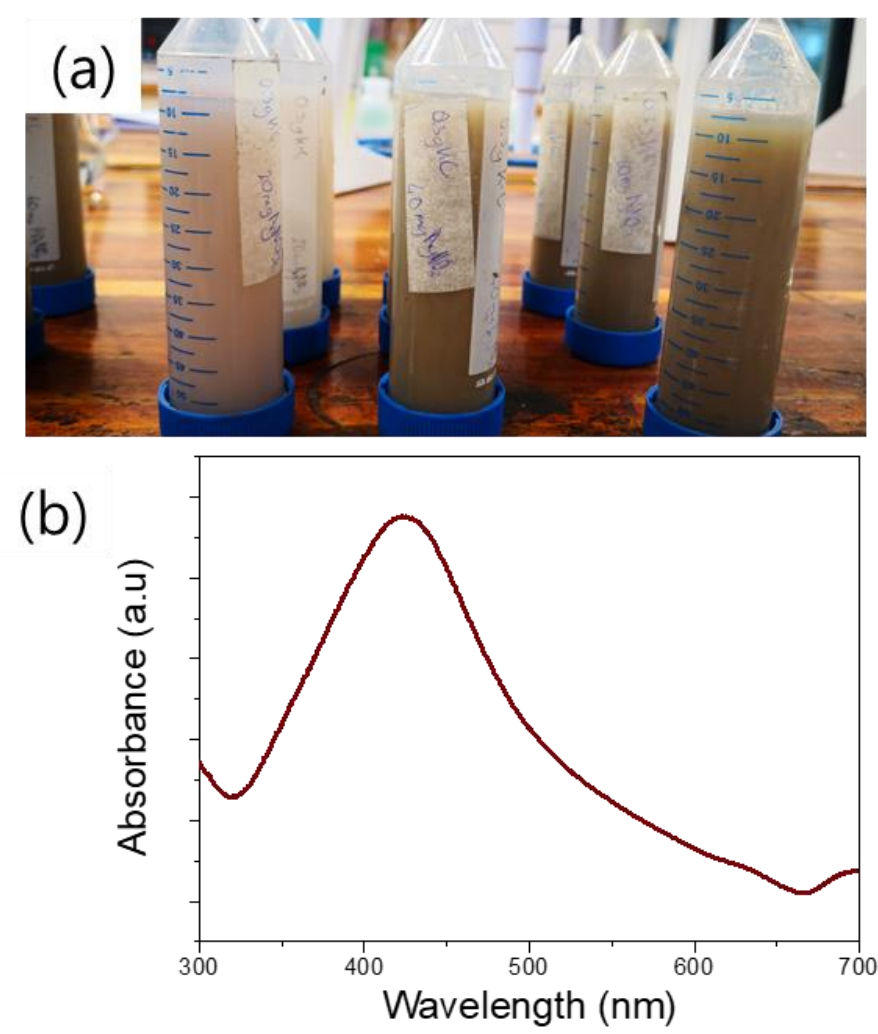

Fig. 2: Visual observation of the formation of CG capped AgNPs synthesis of different ratio of $\mathrm{AgNO}_{3} / \mathrm{CG}$; (b) $\mathrm{UV}$ visible spectra of $\mathrm{CG}$ capped AgNPs showing SPR at 424nm.

The CG-capped AgNPs synthesized in this method are characterized using powder XRD to confirm the particles as silver and to know the structural information. Fig.3a shows the XRD pattern of CG-capped AgNPs. The pattern clearly shows

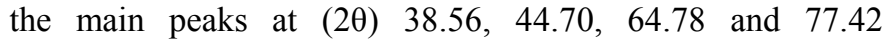
corresponding to the (111), (200), (220) and (311) planes, respectively [57]. By comparing JCPDS (file no: 89-3722), the typical pattern of CG-capped AgNPs is found to possess a face centred cubic (fcc) structure. The surface morphology of CG-capped AgNPs was performed by using SEM micrograph, at two different magnifications (Figure .3b, c). The CG-capped AgNPs showed homogenous dispersion of AgNPs in the matrix of biopolymer (CG). No agglomeration was observed in it. These are our preliminary work, for the confirmation of shape, size and distribution we will perform the TEM in the near future. So those details are not included in this script. (a)
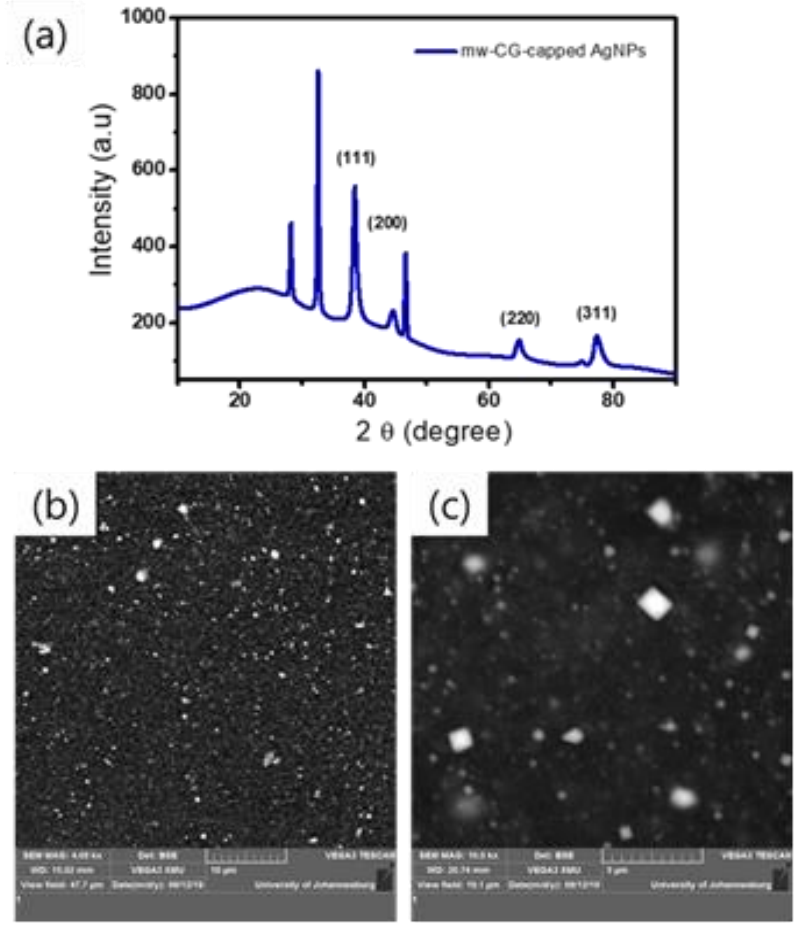

Fig. 3: (a) XRD pattern of CG-capped AgNPs; (b.c) SEM images at two different magnifications.

\section{PHYSICAL CHARACTERISATION RESULTS}

A zeta potential was used to determine the surface potential of the silver nanoparticles. It also provides the information link to stability of our CG-capped AgNPs. The zeta potential analysis results reveaedl that the change in zeta potential was observed with increasing silver nitrate concentrations and by increasing $\kappa$-carrageenan concentration. All the silver nanoparticle solutions had zeta potentials that were negative and smaller than $-30 \mathrm{mV}$. It was already stated that zeta potential value smaller than $-30 \mathrm{mV}$ is indicative of a stable particle indicating that the particles formed have high stability [57] and the zeta potential values did not change after several days clearly confirming the high stability of our CG-capped AgNPs (Fig.4). The compound with the best antimicrobial results had a zeta potential of $-38.17 \mathrm{mV}$.

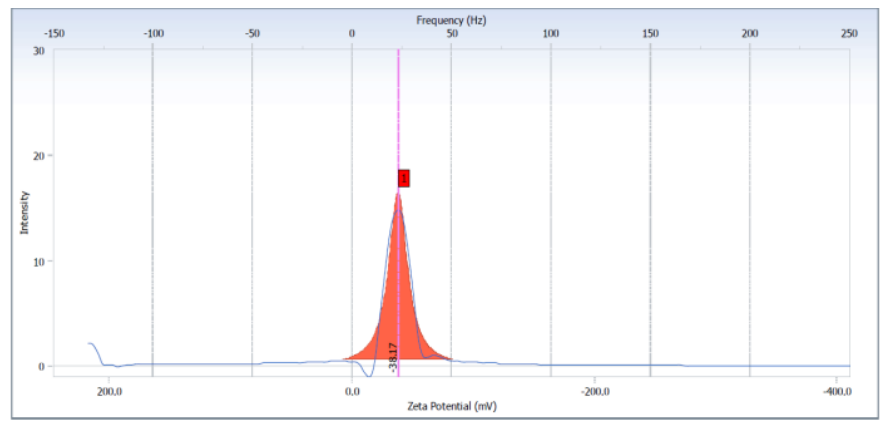

Fig.4 Shows the zeta potential of CG-capped AgNPs-38.17mV and no change was observed after several days 


\section{ANTIMICROBIAL RESULTS}

The growth inhibited zones surrounding the impregnated discs had a max diameter of $7 \mathrm{~mm}$ with the largest inhibition zone being $11 \mathrm{~mm}$ in diameter. This measurement was made on the ( $0.3 \mathrm{~g} \mathrm{CG}-60 \mathrm{mg}$ silver nitrate) $/ 50 \mathrm{~mL}$ solution diluted to a $1: 1$ dilution. This size of inhibition zone for an experimental compound compares well to the $21 \mathrm{~mm}$ inhibition zone measured for the carbenicillin commercial antibiotic. In this case the dilution of the CG-capped AgNPs solution is $33 \%$ as effective as this commercial antibiotic. The vancomycin discs did not significantly inhibit any growth of the E. coli. In Fig. 5(a) the inhibition zone can clearly be seen as a clear growth free circle around the white disc. Fig. 5 (b) is for comparison and represents the carbenicillin control. Some petri dishes showed initial inhibitions were after the bacteria grew further. This was indicated by a set of 2 concentric inhibition zones where the outer zone had some bacterial growth. This can be attributed to resistance to the antimicrobial compound $[59,60]$.

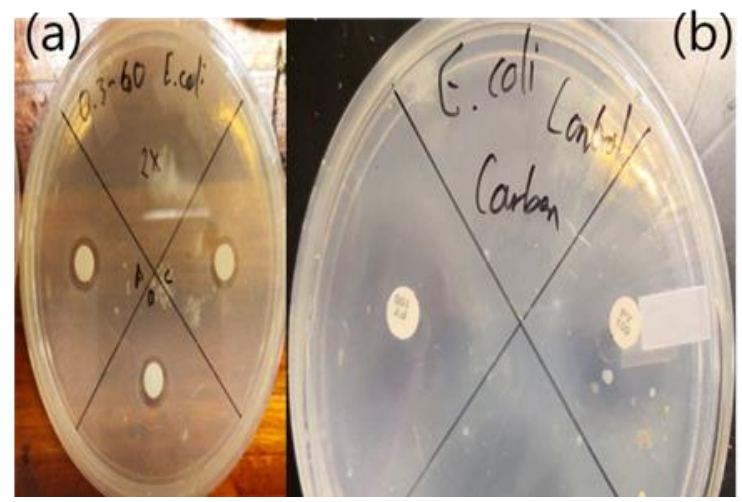

Fig. 5: Inhibition of E. coli by (a) CG-capped AgNPs, (b) carbenicillin

\section{CONCLUSION}

We have successfully synthesised simple, fast, low cost ecofriendly CG-capped AgNPs by using biopolymer, kappa carrageenan gum. The XRD results clearly depict the FCC structure of silver. The zeta potential results confirm the high stability of CG-capped AgNPs. From this study, it was found that CG-capped AgNPs have promising bactericidal activity, although the actual mechanism of antimicrobial action remains to be discovered, the antimicrobial activity exhibited by CG-capped AgNPs makes it a superior nominee for use as bactericidal agents that can be used for several medical applications.

\section{CONFLICT OF INTEREST}

The authors declare no competing financial interest.

\section{ACKNOWLEDGEMENTS}

This study was supported by the National Research Foundation of Korea (NRF) grant funded by the Korea government (MSIT) (No. 2018R1A2B6004746). This work was also supported by Yeungnam University and The Faculty of Engineering, North West University.

\section{REFERENCES}

[1] Donnenfeld, Z, Hedden, S, Crookes, C, 'A Delicate Balance: Water Scarcity in South Africa'. Institute for Security Studies (ISS), 2018.

[2] Elvis Fosso-Kankeu. 2019. Nano and Bio-based Technologies for wastewater treatment: Prediction and Control Tools for the dispersion of Pollutants in the Environment. Wiley Scrivener. ISBN: 978-1-119-57709-6. Pp 301-336.

[3] Elvis Fosso-Kankeu. 2019. New Horizons in Wastewaters Management: Emerging Monitoring and Remediation Strategies. Nova Science Publishers. ISBN: 978-1-53615-659-1.

[4] J.G. Redelinghuys, E. Fosso-Kankeu, G. Gericke, F. Waanders. 2019. Coal Power Plant Wastewater Treatment by Thermal and Membrane Technologies. In Nano and Bio-based Technologies for wastewater treatment: Prediction and Control Tools for the dispersion of Pollutants in the Environment. Editor: Elvis Fosso-Kankeu. Wiley Scrivener. ISBN: 978-1-119-57709-6. Pp 149-168. https://doi.org/10.1002/9781119577119.ch5

[5] N. Mukwevho, E. Fosso-Kankeu, F. Waanders. 2019. PAHs Released from Coal Tars and Potential Removal Using Nanocatalysts. In Nano and Bio-based Technologies for wastewater treatment: Prediction and Control Tools for the dispersion of Pollutants in the Environment. Editor: Elvis Fosso-Kankeu. Wiley Scrivener. ISBN: 978-1-119-57709-6. Pp 169-203. https://doi.org/10.1002/9781119577119.ch6

[6] E. Fosso-Kankeu, P. Jagals, H. Du Preez, Exposure of rural households to toxic cyanobacteria in container-stored water. Water SA, Vol. 34, no. 5, pp. 631-636, 2008.

https://doi.org/10.4314/wsa.v34i5.180660

[7] E. Fosso-Kankeu, A. Mulaba-Bafubiandi, B.B. Mamba, T.G. Barnard, Mitigation of $\mathrm{Ca}, \mathrm{Fe}$, and $\mathrm{Mg}$ loads in surface waters around mining areas using indigenous microorganism strains. Journal of Physics and Chemistry of the Earth, Vol. 34, pp. 825-829, 2009. https://doi.org/10.1016/j.pce.2009.07.005

[8] E. Fosso-Kankeu, H. Du Preez, P. Jagals, The health implication of relationships between bacterial endotoxin, cyanobacteria, coliforms and water stored in domestic containers of rural households in South Africa. Journal of Water and Health, Vol. 8, no. 4, pp. 601-610, 2010. https://doi.org/10.2166/wh.2010.094

[9] E. Fosso-Kankeu, A.F. Mulaba-Bafubiandi, B.B. Mamba, L. Marjanovic, and T.G. Barnard, Optimising the removal by $\mathrm{b}$ subtilis and $\mathrm{b}$ bacterium of metals found around mining areas: evaluation of the effect of physical and physiological parameters. In: Water Institute of Southern Africa \& International Mine Water Association: Proceedings, International Mine Water Conference. International Mine Water Association Conference, Pretoria 2009. ISBN: 978-0-9802623-5-3. 2009.

[10] E. Fosso-Kankeu, A. Mulaba-Bafubiandi, B.B. Mamba, L. Marjanovic, T.G. Barnard, A comprehensive study of physical and physiological parameters that affect biosorption of metal pollutants from aqueous solutions. Journal of Physics and Chemistry of the Earth, Vol. 35, pp. 672-678, 2010. https://doi.org/10.1016/j.pce.2010.07.008

[11] E. Fosso-Kankeu, A. Mulaba-Bafubiandi, B.B. Mamba, T.G. Barnard, Assessing the effectiveness of a biological recovery of nickel from tailings dumps. Journal of Minerals Engineering. Vol. 24, pp. 470-472, 2011. https://doi.org/10.1016/j.mineng.2010.11.007

[12] E. Fosso-Kankeu, A.F. Mulaba-Bafubiandi, B.B. Mamba and T.G. Barnard, Prediction of metal-adsorption behaviour in the remediation of water contamination using indigenous microorganisms. Journal of Environmental Management. Vol. 92, no. 10, pp. 2786-2793, 2011. https://doi.org/10.1016/j.jenvman.2011.06.025

[13] H. Mittal, E. Fosso-Kankeu, Shivani B. Mishra, Ajay K. Mishra, Biosorption potential of Gum ghatti-g-poly (acrylic acid) and susceptibility to biodegradation by B. subtilis. International Journal of Biological Macromolecules. Vol. 62, pp. 370-378, 2013. https://doi.org/10.1016/j.ijbiomac.2013.09.023

[14] E. Fosso-Kankeu, A.F. Mulaba-Bafubiandi, T.G. Barnard, Establishing suitable conditions for metals recovery from metal saturated Bacillaceae bacterium using experimental design. International Biodeterioration and Biodegradation. Vol. 86, pp. 218-224, 2014. https://doi.org/10.1016/j.ibiod.2013.09.022

[15] E. Fosso-Kankeu, A.F. Mulaba-Bafubiandi and T.G. Barnard, Clayey materials in river basin enhancing microbialogical contamination of river 
water. Journal of Physics and Chemistry of the Earth. Vol. 67-69, pp. 236-241, 2014.

https://doi.org/10.1016/j.pce.2013.10.001

[16] South African Government, 'Water and sanitation | South African Government', 2019.2 [Online]. Available: https://www.gov.za/about-sa/water-affairs. [Accessed: 22-Jul-2019].

[17] Abia, A.L.K, Schaefer, L, Ubomba-Jaswa, E, Le Roux, W, Abundance of Pathogenic Escherichia coli Virulence-Associated Genes in Well and Borehole Water Used for Domestic Purposes in a Peri-Urban Community of South Africa. Int. J. Environ. Res. Public Health, 2017, 14, 320 https://doi.org/10.3390/ijerph14030320

[18] Lim, J.Y, Yoon, J.W, Hovde, C.J, A brief overview of Escherichia coli O157:H7 and its plasmid O157. Journal of Microbiology and Biotechnology. 2010, 5-14. https://doi.org/10.4014/jmb.0908.08007

[19] Dufour, A, Escherichia coli: The Fecal Coliform, in Bacterial Indicators/Health Hazards Associated with Water, 100 Barr Harbor Drive, PO Box C700, West Conshohocken, PA 19428-2959: ASTM International, 1977, 48-11

[20] Blom, N, Vaal district faces catastrophe as Emfuleni sewage spills into river', BusinessDay, 2018. [Online]. Available: https://www.businesslive.co.za/bd/national/science-and-environment/20 18-07-31-emfuleni-faces-catastrophe-as-sewage-threatens-crops-and-tou rism/. [Accessed: 22-Jul-2019].

[21] Pandey S, A comprehensive review on recent developments in bentonite based materials used as adsorbents for wastewater treatment. Journal of Molecular Liquids 2017, 241, 1091-1113. https://doi.org/10.1016/j.molliq.2017.06.115

[22] Pandey S. Highly Sensitive and Selective Chemiresistor Gas/Vapor Sensors based on Polyaniline Nanocomposite: A comprehensive review. J Sci Adv Mate Devic. 2016,1, 431-453. https://doi.org/10.1016/j.jsamd.2016.10.005

[23] Pandey S, Goswami GK, Okoro HK, Fosso-Kankeu E Carbon Nanotubes in the 21st Century: An Advancement in Real Time Monitoring and Control of Environmental Water., Nano and Bio-Based Technologies for Wastewater Treatment (Chapter.8) 2019, 1, 265-301. ISBN: 9781119577119 https://doi.org/10.1002/9781119577119.ch8

[24] E. Fosso-Kankeu, F. Waanders, M. Geldenhuys, Impact of nanoparticles shape and dye property on the photocatalytic degradation activity of $\mathrm{TiO}$. International Journal of Science and Research. Vol. 5 , no. 11, pp. $528-535,2016$

[25] E. Fosso-Kankeu, H. Mittal, F. Waanders, S.S. Ray, Thermodynamic properties and adsorption behaviour of hydrogel nanocomposites for cadmium removal from mine effluents. Journal of Industrial and Engineering Chemistry. Vol. 48, pp. 151-161, 2017. https://doi.org/10.1016/j.jiec.2016.12.033

[26] C. de Klerk, E. Fosso-Kankeu, F.B. Waanders, Evaluation of the antibacterial activity of metal impregnated multi-walled carbon nanotubes: impact of domestic wastewater as supporting medium. Desalination and Water Treatment.Vol. 99, pp. 272-281, 2017. https://doi.org/10.5004/dwt.2017.21735

[27] A. Leudjo Taka, E. Fosso-Kankeu, K. Pillay, X. Yangkou Mbianda, Removal of cobalt and lead ions from wastewater samples using an insoluble nanosponge biopolymer composite: Adsorption isotherms, kinetics, thermodynamics and regeneration studies. Environmental Science and Pollution Research. 2018.

[28] N. Mukwevho, E. Fosso-Kankeu, F. Waanders, N. Kumar, S.S. Ray, X.Y. Mbianda, Evaluation of the photocatalytic activity of $\mathrm{Gd}_{2} \mathrm{O}_{2} \mathrm{CO}_{3} . \mathrm{ZnO} . \mathrm{CuO}$ nanocomposite used for the degradation of phenanthrene. Springer Nature Applied Sciences. 2018. https://doi.org/10.1007/s42452-018-0012-0

[29] Sadanand Pandey, Gopal Krishna Goswami, Hussein Kehinde Okoro, Elvis Fosso-Kankeu. 2019.Carbon nanotubes in the 21st Century: An Advancement in real time monitoring and control of environmental water. In Nano and Bio-based Technologies for wastewater treatment: Prediction and Control Tools for the dispersion of Pollutants in the Environment. Editor: Elvis Fosso-Kankeu. Wiley Scrivener. ISBN: 978-1-119-57709-6. Pp 263-300.

[30] Corli de Klerk,Elvis Fosso-Kankeu and Frans Waanders. 2019. Nanoparticle-biopolymer antimicrobial compounds as sustainable option for wastewater treatment. In New Horizons in Wastewaters Management:
Emerging Monitoring and Remediation Strategies. Editor: Elvis Fosso-Kankeu. Nova Science Publishers. ISBN: 978-1-53615-659-1.

[31] Elvis Fosso-Kankeu, Antoine F Mulaba-Bafubiandi and Ajay K Mishra. 2014. Prospects in the immobilization of microbial sorbents on carbon nanotubes for biosorption: Bioremediation of heavy metals polluted water. In: Mishra A.K. (Eds). Application of Nanotechnology in Water Research. Wiley, Scrivener Publisher. ISBN: 978-1-118-49630-5. https://doi.org/10.1002/9781118939314.ch3

[32] Elvis Fosso-Kankeu and Ajay Kumar Mishra. 2017. Photocatalytic degradation and adsorption techniques involving nanomaterials for biotoxins removal from drinking water. In: Alexandru Grumezescu (Eds). Water Purification. Academic Press, Elsevier. ISBN: 9780128043004. https://doi.org/10.1016/B978-0-12-804300-00009-5. Pp 323 - 354.

[33] E. Fosso-Kankeu, F. Waanders, and M. Geldenhuys, Photocatalytic Degradation of Dyes using $\mathrm{TiO}_{2}$ Nanoparticles of Different Shapes. $7^{\text {th }}$ International Conference on Latest Trends in Engineering and Technology (ICLTET' 2015), November 26-27, 2015 Irene, Pretoria (South Africa). Award Winning Paper. Editors: E. Muzenda and T Yingthawornsuk. ISBN: 978-93-84422-58-5. 2015.

[34] E. Fosso-Kankeu, H. Mittal, F. Waanders, S.S. Ray, Performance of synthesized hybrid hydrogel nanocomposite applied for the removal of metal ions from aqueous solutions. In: Drebenstedt, C. \& Paul, M.: IMWA 2016 - Mining Meets Water - Conflicts and Solutions. - p. 850 857; Freiberg/Germany (TU Bergakademie Freiberg). 2016.

[35] E. Fosso-Kankeu, C.M. De Klerk, T.A. Botha, F. Waanders, J. Phoku, S. Pandey, The antifungal activities of multi-walled carbon nanotubes decorated with silver, copper and zinc oxide particles. International Conference on Advances in Science, Engineering, Technology and Natural Resources (ICASETNR-16) Nov. 24-25, 2016, Parys - South Africa. ISBN: 978-93-84468-79-8. 2016.

[36] C.M. De Klerk, E. Fosso-Kankeu, F. Waanders, Antifungal activities of chitosan and nanoparticle derivatives under various $\mathrm{pH}$ conditions. International Conference on Advances in Science, Engineering, Technology and Natural Resources (ICASETNR-16) Nov. 24-25, 2016, Parys - South Africa. ISBN: 978-93-84468-79-8. 2016.

[37] N. Mukwevho, E. Fosso-Kankeu, F. Waanders, G. Gericke, J. Bunt, Synthesis and characterization of $\mathrm{ZnO}$ nanoparticle and application in the photodegradation of organic pollutants in effluents from coal power station. International Conference on Advances in Science, Engineering, Technology and Natural Resources (ICASETNR-16) Nov. 24-25, 2016, Parys - South Africa. ISBN: 978-93-84468-79-8. 2016.

[38] C. de Klerk, E. Fosso-Kankeu, L. du Plessis, F. Waanders, Domestic wastewater treatment: The influence of silver impregnated polyrhodanine nanofibers on Gram-positive and Gram-negative bacteria. $9^{\text {th }}$ Int'l Conference on Advances in Science, Engineering, Technology \& Waste Management (ASETWM-17). 27-28 November 2017, Parys, South Africa. Editors: F. Waanders, E. Fosso-Kankeu, B. Topcuoglu, M. Plaisent, Y. Thaweesak. ISBN: 978-81-934174-6-1. Pp. 152-157. 2017.

[39] S. Pandey, E. Fosso-Kankeu, J. Ramontja, Efficient and rapid adsorption characteristics of templating xanthan gum-graft-poly (aniline) and silica nanocomposite toward removal of toxic methylene blue dyes. ${ }^{\text {th }}$ Int'l Conference on Advances in Science, Engineering, Technology \& Waste Management (ASETWM-17). 27-28 November 2017, Parys, South Africa. Editors: F. Waanders, E. Fosso-Kankeu, B. Topcuoglu, M. Plaisent, Y. Thaweesak. ISBN: 978-81-934174-6-1. Pp. 175-180. 2017.

[40] Pandey S, Nanda K. Au Nanocomposite Based Chemiresistive Ammonia Sensor for Health Monitoring. ACS Sensors.2015;1(1):55-62. https://doi.org/10.1021/acssensors.5b00013

[41] Pandey S, Mishra S. Bioceramics: Silica- Based Organic- Inorganic Hybrid Materials for Medical Applications. Nanomedicine for Drug Delivery and Therapeutics: John Wiley \& Sons, Inc.; 2013. p. 135-61. https://doi.org/10.1002/9781118636299.ch5

[42] Marambio-Jones, C, Hoek, E.M.V, A review of the antibacterial effects of silver nanomaterials and potential implications for human health and the environment. Journal of Nanoparticle Research. 2010,12, 1531-1551. https://doi.org/10.1007/s11051-010-9900-y

[43] Singh, V, Tiwari, A, Pandey, S, Singh, SK, Peroxydisulfate initiated synthesis of potato starch-graft-poly (acrylonitrile) under microwave irradiation, Express Polymer Letters 2007, 1 (1), 51-58 https://doi.org/10.3144/expresspolymlett.2007.10 
[44] Korbekandi, H, Ashari, Z, Irvani, S, Abbasi, S, Optimization of Biological Synthesis of Silver Nanoparticles using Fusarium oxysporum. Iran. J. Pharm. Res., 2013, 12, 289-298.

[45] Cittrarasu, V et al., Biological mediated Ag nanoparticles from Barleria longiflora for antimicrobial activity and photocatalytic degradation using methylene blue. Artif. Cells, Nanomedicine Biotechnol., 2019, 2424-2430. https://doi.org/10.1080/21691401.2019.1626407.

[46] Karimi, S, Samimi, T, Green and simple synthesis route of $\mathrm{Ag} @ \mathrm{AgCl}$ nanomaterial using green marine crude extract and its application for sensitive and selective determination of mercury. Spectrochim. Acta Part A Mol. Biomol. Spectrosc., 2019, 222, 117216. https://doi.org/10.1016/j.saa.2019.117216

[47] Anand Mariadoss, A.V. et al., Green synthesis, characterization and antibacterial activity of silver nanoparticles by Malus domestica and its cytotoxic effect on (MCF-7) cell line. Microb. Pathog., 2019, 135, 103609.

https://doi.org/10.1016/j.micpath.2019.103609

[48] Pandey, S, Goswami, G.K, Nanda, K.K, Green synthesis of biopolymer-silver nanoparticle nanocomposite: An optical sensor for ammonia detection, International journal of biological macromolecules 51 (4), 583-589 https://doi.org/10.1016/j.ijbiomac.2012.06.033

[49] Jahan, I, Erci, F, Isildak, I, Microwave-Assisted Green Synthesis of Non-Cytotoxic Silver Nanoparticles Using the Aqueous Extract of Rosa santana (rose) Petals and Their Antimicrobial Activity. Anal. Lett., 2019, $52,1860-1873$. https://doi.org/10.1080/00032719.2019.1572179

[50] Makhado, E. Pandey, S. Ramontja, J. Microwave-assisted green synthesis of xanthan gum grafted diethylamino ethyl methacrylate: an efficient adsorption of hexavalent chromium, Carbohydr. Polym., 2019, 222, 114989. https://doi.org/10.1016/j.carbpol.2019.114989

[51] Makhado, E. Pandey, S. Nomngongo, P. Ramontja, J, Preparation and characterization of xanthan gum-cl-poly (acrylic acid)/o-MWCNTs hydrogel nanocomposite as highly effective re-usable adsorbent for of methylene blue from aqueous solutions. Journal of Colloid and Interface Science, 2018, 513,700-714. https://doi.org/10.1016/j.jcis.2017.11.060

[52] Singh, V., Tiwari, A., Pandey, S, Singh, SK, Microwave-accelerated Synthesis and Characterization of Potato Starch- g-poly (acrylamide), Starch-Stärke 58 (10), 536-543 https://doi.org/10.1002/star.200600520

[53] Pandey S, Kang, M, 1P-685: Fast microwave-assisted green synthesis of locust bean gum grafted diethylamino ethyl methacrylate: An efficient metal ion removal, The Korean Society of Industrial and Engineering Chemistry, 2019, 274.

[54] Siby, J., Beena, M. Microwave-assisted facile green synthesis of silver nanoparticles. Bull. Mater. Sci., 2015, 38, 1-8.

[55] Makhluf, S., Dror, R., Nitzan Y., Y. Abramovich, Y., Jelinek, R., Gedanken, A., Microwave-assisted synthesis of nanocrystalline $\mathrm{MgO}$ and its use as a bacteriocide. Adv. Funct. Mater. 2005, 15, 1708-1715. https://doi.org/10.1002/adfm.200500029

[56] Rani, G.N., Budumuru, R., Bandaru, N.R., Antimicrobial activity of honey with special reference to methicillin resistant staphylococcus aureus (MRSA) and methicillin sensitive staphylococcus aureus (MSSA), J. Clin. Diagnostic Res. 2017, 11, DC05-DC08. https://doi.org/10.7860/JCDR/2017/30085.10347

[57] Pandey, S, Goswami, G.K, Nanda, K.K, Nanocomposite based flexible ultrasensitive resistive gas sensor for chemical reactions studies, Nature Scientific Reports 2013, 3 (2082), DOI:10.1038/srep02082 (2013)

[58] Pandey, S, Ramontja, J Sodium alginate stabilized silver nanoparticles-silica nanohybrid and their antibacterial Characteristics, International Journal of Biological Macromolecules 2016, 93 (A), 712-723 https://doi.org/10.1016/j.ijbiomac.2016.09.033

[59] Gaudreau, C., Gilbert, H., Comparison of disc diffusion and agar dilution methods for antibiotic susceptibility testing of Campylobacter jejuni subsp. jejuni and Campylobacter coli. J. Antimicrob. Chemother. 1997, 39, 707-712. https://doi.org/10.1093/jac/39.6.707

[60] Fosso-Kankeu, E., De Klerk, C.M., Van Aarde, C., Waanders, F., Phoku, J., Pandey, S., Antibacterial Activity of a Synthesized Chitosan-Silver
Composite with Different Molecular Weights Chitosan against Gram-Positive and Gram-Negative Bacteria, Int'l Conf. on Advances in Science, Engineering, Technology \& Natural Resources (ICASETNR-16), 2016, 142-146. 